\title{
Arab Learners of English and the Use of Discourse Markers in Writing
}

\author{
Farah Mohammad Al Mughrabi \\ Department of English, The Hashemite University, Jordan
}

\begin{abstract}
This study aims at investigating the development level of Arab EFL learners in the use of discourse markers (DMs) in writing through the analysis of their errors. For this purpose, two types of questions regarding the use of DMs (additive, causative, adversative, and temporal) were distributed to 40 undergraduates (20 males \& 20 females), first, second, third, and fourth year English-major, in the academic year 2015, at the Hashemite University in Jordan. The study concludes that students' level in using DMs becoming better and better as their academic level evolves.
\end{abstract}

Index Terms — discourse markers, EFL learners, academic level, writing process

\section{INTRODUCTION}

Discourse, weather spoken or written, is a way of communication and interaction between people in which they use language as a means to give and take information, and to express their ideas and feelings toward others. As Dijk (1985) states "discourse usually refers to a form of language use, public speeches or more generally to spoken language or ways of speaking", he also adds that analysts of discourse agree that it means language in use (pp. 1-2). The purpose of discourse or communication between people is to convey the right meaning or the required message. In order to fulfill this aim discourse has different markers, linking words, or cohesive devices; like, because, but, so, and, however, etc. that people should use. As Holmqvist and Holsanova (1997) say "discourse consists of small units and includes small words (discourse markers) that reflect the planning and production process of the speaker" (p. 224). These markers have several terms that used interchangeably to refer to the same idea, as Fraser (1999) states "these lexical expressions have been studied under various labels, including discourse markers, discourse connectors, discourse operator, pragmatic connectives, sentence connectives, and cue phrases"(p.931).

(Note: the terms, discourse markers, linking words and cohesive devices will be used interchangeably in this paper).

According to Saez (2003) there are two types of information that DMs convey; "attitudinal comments of the speaker or information about the connections between utterances" (p. 348). Therefore, discourse markers either function as indicators to know what the next utterance is, or as linking words which connect words, sentences, and phrases together. The first role is more connected with the spoken discourse, whereas the second one is more associated with the written one, which is our concern in this paper. The use of DMs in the writing process is more important than using them in oral conversation; in that in spoken discourse a hearer can know the right meaning by other way rather than the use of signals; such as, gestures, facial expression, and body language. But, in written discourse a reader has nothing but the text, thus the writer should include markers and cohesive devices that enable the reader to move smoothly from one idea to another and to understand what in the text is going on. So, linking words help to connect ideas together so one can understand the general idea and pay more attention to a certain notion, and off course they help to produce more cohesive texts.

Discourse markers are basically linking words that stick words and sentences together. These cohesive devices are various and different, and they can occur at any place in oral or written discourse; at the beginning, in the middle, or at the end. Fraser (1999) suggests that discourse markers refer to three syntactic categories; conjunctions, adverbs, and prepositional phrases. Also, Asassfeh, Alshboul, and Alshaboul (2013) suggest that there are four distinct categories of logical connectors (LCs): additive, causative, adversative, and temporal connectors. Additive markers like and, furthermore, moreover, besides, in addition... etc, are used to add and explain ideas. Causative markers; such as because, so, therefore, as a result, thus... etc, connect ideas by signaling the next sentence as a consequent, result, or reason for the previous one. Adversative markers like but, yet, instead, on the other hand, although...etc. show contrasts between two sentences; the sentence precedes the marker and the sentence that follows. The last class is temporal or sequential markers which mark a chronological order of ideas; such as, first, firstly, second, next, finally... etc. This study is concerned with the use of these four classes.

Almost all countries of the world use English as a second language because it is an intermediate one which people speak to understand each other's language. In most Arab countries, all students learn English at public schools for about seven years and at private schools nearly for twelve years, but unfortunately their level in English as a foreign is not good especially in the writing skill. As noticed by many researchers, one important feature that learners fail to use properly in their writings is DMs. The aim of this paper is to examine the development level of Arab EFL learners 
regarding the use of cohesive devices in the writing process, with respect to the use of four categories: additives, causatives, adversatives, and temporal markers.

\section{A. Problem Statement}

Almost all learners of a second language make errors in different parts of the writing process; syntax, linking words, punctuation, vocabulary, spelling, and many others. But, errors that are related to the use of discourse markers are the most important ones; because the quality of writing is majored by their usage. According to Daif-Allah \& Albesher (2013), the "awareness of the use and practicality of DMs can immensely contribute to the overall quality of the discourse created by English language learners" (p. 218). Thus, the more is the use of appropriate cohesive devices, the more is the production of cohesive texts. As it is mentioned before, meaning cannot be understood without using or applying connectivity tools rightly. For example, the following sentences have different meanings:

A. - John cannot go out on Mondays, Tuesdays, and Wednesday.

- John cannot go out on Mondays, Tuesdays, or Wednesdays.

B. - I like my aunt because I don't see her frequently.

- I like my aunt, but I don't see her frequently.

The linking words (and, or, because, but) change the whole interpretation in both examples; in the first example 'and' indicates that John cannot go out in all these three days, while 'or' marks that there is a possibility to go out in at least one of these days. Similarly, in the second example, the use of causative and contrastive markers (because \& but) affects the meaning; because they function differently in connecting words together. Therefore, applying the wrong discourse marker in the wrong place is a serious problem that may result in creating different interpretation. Various meanings lead to misunderstanding of a piece of information, which in turn affects the quality of the text that indicates weakness in the writing skill.

\section{B. Objectives of the Study}

This study concentrates on answering the following questions:

1. What is the most frequent error/s in terms of the use of four classes of DMs; additive, causative, adversative, and sequential markers that Arab EFL learners make?

2. Which kind of questions do students find more difficult to answer; filling in the blanks, or choosing the right position for DMs?

3. Is there a remarkable development regards students' use of linking words through their four years of study?

\section{Rationale of the Study}

Writing skill is the most complex part of language; both to teach and to learn. It is very important for learners to learn how to write effectively because as Haselow (2011) says "writing is seen basically as a process of four main stages: planning, drafting, revising, and editing" (p. 3603-3623). Applying DMs is one of the major sections that must be included in writing. Many researchers conducted studies about the use of DMs by Arab EFL learners, but a few studies were carried out in Jordan to investigate the developmental level of proficiency. So, this study is important because:

- Few studies were conducted in this field in Jordan.

- It opens the way for learners to focus more on the learning process with respect to the use of DMs.

- It opens the way for teachers to change teaching techniques and improving them.

\section{Significance of the Study}

The significance of this study is derived from its purposes; that focus on revealing the most common kinds of DMs Arab learner of English (English-majors students of the Hashemite University in specific) find difficulties in applying them correctly; and therefore using them wrongly. Finding errors students make opens the way to discover solutions. So, the main significance of this study is to understand the basic problems that students face in applying DMs in order to tackle them in appropriate ways. Like, to change and develop teaching techniques according to learners' level of proficiency, aware students of the bad consequences of using cohesive devices wrongly especially in their writings. The most important point is to encourage them by various ways to put much effort in the learning process; by understanding how to use different DMs in different situations and positions according to their functions rather than just memorizing them.

\section{E. Hypotheses/Predicted Results}

There are three main hypotheses for this study:

1. It was predicted that the most frequent error English-major students commit in the use of DMs is related to the adversative class (instead and although), followed by causative (because, so, in order to), additive (and, or, for example), and sequential (first, second, third) categories. This prediction is derived from the researcher's knowledge that students do not use adversative markers frequently, so they possibly do not know their functions or usages.

2. It was predicted that students are more likely to face difficulties in answering the second question than the first one. In the first question, linking words and positions are given to students, whereas in the second they are just given the categories of DMs in which they have to guess their places. 
3. It was hypothesized that the number of errors made by third and fourth-year students is much less than that committed by first and second-year students.

After first and second years of study, students somehow become more recognizable of the structure of words and sentences in the writing process; because most of them take writing courses (writing 1 and advanced writing) in their first and second years. Thus, they are expected to link ideas and sentences, and write more cohesive paragraphs in their third and fourth years.

\section{LITERATURE REVIEW}

Facing problems, in general, and committing errors in learning a second language are serious phenomena that many researchers and linguists have written about. Al Quran (2010) states that "The belief that making errors is an inevitable component of learning in both first and second language learning is what underlies the continued interest in error analysis" (p. 2). The most important but difficult part for learners in learning a second language is writing; as AlBuainain (2006) claims that "writing is especially difficult for non-native speakers because learners are expected to create written products that demonstrate their ability to organize the content" (p. 18). So, the writing process is a hard skill because it is all about delivering the right or the meant meaning; by organizing ideas, connecting words and sentences in the suitable form, using the right grammar, choosing the right vocabulary, using the appropriate punctuation ...etc. one can infer the meaning of any given text. Discourse markers (cohesive devices) play a significant part in the composition of writing; that is when linking or connecting the backward sentence with the forward one by using the right linking word, one can figure out the relation between the two sentences and the meaning they express.

Making errors in the use of discourse markers is one of the major issues that Arab learners of English encounter especially in the writing process; therefore, many researchers conducted studies about the different use of cohesive devices and the common mistakes that Arab EFL learners make when using them. For example, Martines (2002) carried out a study at the University of Oviedo in order to examine the use of discourse markers by Spanish EFL learners. Seven essays were written by seven English-major students about a linguistic topic; the analysis of their conclusion part showed that participants used markers appropriately, but some of them overused some kinds and underused others. Also, Sadighi and Heydari (2012) conducted a study to investigate the most frequent cohesive errors made by Iranian undergraduate students, according to the level of proficiency, who learn English at Shiraz Azad University. 67 male and female were asked to write a narrative composition, they found out that the most frequent error was the use of references, followed by lexical and conjunctive devices. In other context, Modhish (2012) analyzed 50 essays written by Yemeni EFL students of level three who are enrolled in the four-year undergraduate program at TU, Yemen; and that to find out the frequency usage of discourse markers. He discovered that students used elaborative, inferential, contrastive, causative, and topic relating markers respectively. In another study, Asassfeh, Alshboul, and Alshaboul (2013) analyzed the written errors in the use of additive, causative, sequential, and adversative DMs committed by 146 Jordanian English-major undergraduates. The results show that the most frequent errors students made were related to additive, causative, adversative, and sequential respectively.

We can see from the review of literature that many researchers conducted studies to find out the frequent errors made by Arab EFL learners regards the use of different types of DMs. But, few researchers emphasized on the students' level of proficiency in using them. The purpose of this paper is to examine the most common kinds of cohesive devices made by Arab students at the Hashemite University in Jordan which in turn reveal their development level.

\section{Methodology}

\section{A. Participants}

This paper is based on data collected randomly from the answers of 40 students (20 males \& 20 females), first, second, third, and fourth-year English majors. 10 students were selected from each year (5 males and 5 females), in the academic year 2015 at the Hashemite University in Jordan.

\section{B. Data Description}

The purpose of this paper is to examine the development level of Arab students, who study and learn English, concerning the use of DMs in the writing process, and to find out the most frequent errors that they make in using linking words. In order to fulfill these aims; two forms of question were distributed randomly to 40 students (20 males and 20 females). The first exercise is to fill in the blank with the appropriate discourse markers in a given paragraph, and the second one is to find the right positions for a given group of linking words in a non-cohesive paragraph. The two paragraphs are selected from a writing book (Savage \& Mayer, 2005) and edited by the researcher to serve the need of DMs. The category of linking words is given in both questions (see questions no $1 \& 2$ in appendixes).

\section{Data Analysis}

This study is an empirical one which contains data collected from the answers of Arab EFL learners. Students were asked to answer two questions regards the use of linking words, they were given no more than 15 minute to answer. Data were analyzed to extract the most common kind of cohesive devices that students use mistakenly; mistakes or 
errors are related to: additive (and, for example, or), causative (because, so, in order to), adversative (instead, although), and sequential (first, second, third). The correction of the papers was done by the researcher; it was limited to identify the most frequent DMs that students use wrongly in order to detect whether students' level of proficiency would really develop and change from the first year to the fourth or would not. The purpose of this research is to find helpful ways and solutions for avoiding such errors; to produce more cohesive texts and achieve better communication between the writer and the reader by understanding the right meaning.

\section{Discussion and Results}

The major concern of this study is to reveal the most common kinds of DMs among additive (and, or, for example), causative (because, so, in order to), adversative (instead, although), and sequential (first, second, third) ones which students find difficulties in using them properly. The analysis of the 40 papers indicated that the total number of errors that were committed by students concerning the use of the four categories of DMs is 187 . Three results were found in this paper in which they answer the three previous research questions. The following tables illustrate the results.

TABLE 1

\begin{tabular}{|l|l|l|}
\hline Type of DMs & Frequency of errors & Percentage of Errors \\
\hline Additive & 42 & $23 \%$ \\
\hline Causative & 92 & $49 \%$ \\
\hline Adversative & 38 & $20 \%$ \\
\hline Sequential & 15 & $8 \%$ \\
\hline Total & $\mathbf{1 8 7}$ & $\mathbf{1 0 0 \%}$ \\
\hline
\end{tabular}

TABLE (1), A

\begin{tabular}{|c|c|c|}
\hline Additive DMs & Frequency of errors & Percentage of Errors \\
\hline And & 2 & $5 \%$ \\
\hline For example & 12 & $28 \%$ \\
\hline Or & 28 & $67 \%$ \\
\hline Total & 42 & $100 \%$ \\
\hline \multicolumn{3}{|c|}{ TABLE (1), B } \\
\hline Causative DMs & Frequency of errors & Percentage of Errors \\
\hline Because & 48 & $52 \%$ \\
\hline So & 13 & $14 \%$ \\
\hline In order to & 31 & $34 \%$ \\
\hline Total & 92 & $100 \%$ \\
\hline
\end{tabular}

TABLE (1), C

\begin{tabular}{|l|l|l|}
\hline Adversative DMs & Frequency of errors & Percentage of Errors \\
\hline Instead & 25 & $66 \%$ \\
\hline Although & 13 & $34 \%$ \\
\hline Total & $\mathbf{3 8}$ & $\mathbf{1 0 0 \%}$ \\
\hline
\end{tabular}

TABLE (1), D

\begin{tabular}{|l|l|l|}
\hline Sequential DMs & Frequency of errors & Percentage of Errors \\
\hline First & 2 & $14 \%$ \\
\hline Second & 5 & $33 \%$ \\
\hline Third & 8 & $53 \%$ \\
\hline Total & $\mathbf{1 5}$ & $\mathbf{1 0 0 \%}$ \\
\hline
\end{tabular}

Table 1 shows the first result in terms of types of cohesive devices. Unpredictably, the findings show that the most common kind of cohesive devices students make errors in, in both exercises, is causative (49\%), followed by additive (22\%), adversative (20\%), and the least difficult is sequential (8\%). Tables (1) A, B, C, \& D show in details the most common mistake of each type of DMs that students make. In the use of additive DMs, most students didn't know what the right position is for 'or' $(66 \%)$, (See table 1). In the second type which is causative, 'because' (52\%) was more problematic for students than 'so' \& 'in order to' to apply. Concerning errors that related to adversative markers, students made mistakes in the use of 'instead' $(65 \%)$ more than 'although'. While in the sequential markers, the highest number of mistakes was in the use of 'third' (53\%) among 'first' \& 'second'.

As hypothesized, the second outcome in table 2 points out that students face more difficulties in answering the second question (to choose the right position for DMs) than the first one (to fill out empty slots). The results indicate that $69,51 \%$ (almost $70 \%$ ) of errors is related to the second question, whereas just $30 \%$ is related to those concerning the first question (see table 2). A reasonable explanation for such result is that either students do not fully know the different functions of linking words, so they cannot choose the suitable or the right place to put them in. Or they did not understand some words and sentences, or the whole idea of the given paragraph, which resulted in facing difficulties in knowing which sentences express cause/effect, addition, or contrastive relation with others.

As expected, the last result that answers the third research question indicates that students' level of proficiency regards using DMs in writing did develop and change through their four years of study. Table 2 demonstrates the result. 
TABLE 2

\begin{tabular}{|l|l|l|}
\hline Year of study & Frequency of Errors & Percentage of Errors \\
\hline First & 57 & $30 \%$ \\
\hline Second & 54 & $29 \%$ \\
\hline Third & 50 & $27 \%$ \\
\hline Fourth & 26 & $14 \%$ \\
\hline Total & $\mathbf{1 8 7}$ & $\mathbf{1 0 0 \%}$ \\
\hline
\end{tabular}

Table 2 manifests the development level of English-major students regards the use of DMs according to their years of study; first, second, third, and fourth years. It fortunately shows that students' level of learning DMs does positively develop when moving from one stage to another. As it is mentioned before, the majority of students tend to register in writing courses in their first and second year. Thus, their writings are expected to be better in the third and fourth year. The findings indicate that there is a noticeable difference in students' answers in both questions; to choose the suitable position and to fill in the blank. In that, the number of errors declined gradually from the first year to the fourth. The percentages of mistakes that were committed by first, second, third, and fourth year students are, 30\%, 29\%, 27\%, and $14 \%$ respectively.

\section{CONCLUSION}

To sum up, making errors in learning a second language is something unavoidable, as AbiSamra (2003) claims that "errors are 'indispensible', since the making of errors can be regarded as a device the learner uses in order to learn" (p. 6). Discourse markers, cohesive devices, or linking words are considered as a necessary part in writing; so as to help connecting ideas and produce a well written text in terms of meaning and cohesion. This study examined the errors Arab learners of English commit concerning the use of linking words. The results show that the percentages of committing mistakes in applying the four kinds of cohesive devices; causative, additive, adversative, and sequential are: $49 \%, 22 \%, 20 \%, \& 8 \%$ respectively.

Although most students and learners of English have learned what DMs are and what functions they serve, they still find difficulties in applying them correctly. In that, in nearly all cases, they seem to be unsure of which, how, when, and where to use them. Actually, most students face this problem which deprives them from producing a well formed paragraph. And that because most of the time, students are asked to answer multiple choice and true/false kinds of question. These types are not helpful because they show nothing about students' writing skill. Asking them to write a paragraph or an essay on a certain topic is much better because in this way one can clearly tell what their writing level is. That's because writing skill is "a clear proof of whether learners learnt English well or not" (Khan \& Akter, 2011, p. 11). Also, teaching techniques affect the learning process both negatively and positively depending on the method used. Some studies were conducted to find helpful methods for teaching Arab learners of English. For instance, Ansari (2012) conducted a study on the problems of teaching English and their remedies in Saudi Arabia, he stated that choosing suitable methods of teaching depends on the need of students; if they are beginners, intermediate, or advanced. Also he concluded that reading process is the first and the most important process which enables learners to write and speak. So, I recommend conducting more studies that aim to analyze all kinds of DMs that learners use inappropriately. Also, other studies my carry out on finding and discovering new helpful techniques in learning how to write with the flavor of cohesive devices.

\section{APPENDIXES}

TABLE 1

\begin{tabular}{|l|l|l|}
\hline Type of DMs & Frequency of errors & Percentage of Errors \\
\hline Additive & 42 & $23 \%$ \\
\hline Causative & 92 & $49 \%$ \\
\hline Adversative & 38 & $20 \%$ \\
\hline Sequential & 15 & $8 \%$ \\
\hline Total & $\mathbf{1 8 7}$ & $\mathbf{1 0 0 \%}$ \\
\hline
\end{tabular}

TABLE (1), A

\begin{tabular}{|l|l|l|}
\hline Additive DMs & Frequency of errors & Percentage of Errors \\
\hline And & 2 & $5 \%$ \\
\hline For example & 12 & $28 \%$ \\
\hline Or & 28 & $67 \%$ \\
\hline Total & $\mathbf{4 2}$ & $\mathbf{1 0 0 \%}$ \\
\hline
\end{tabular}

TABLE (1), B

\begin{tabular}{|l|l|l|}
\hline Causative DMs & Frequency of errors & Percentage of Errors \\
\hline Because & 48 & $52 \%$ \\
\hline So & 13 & $14 \%$ \\
\hline In order to & 31 & $34 \%$ \\
\hline Total & $\mathbf{9 2}$ & $\mathbf{1 0 0 \%}$ \\
\hline
\end{tabular}


TABLE (1), C

\begin{tabular}{|l|l|l|}
\hline Adversative DMs & Frequency of errors & Percentage of Errors \\
\hline Instead & 25 & $66 \%$ \\
\hline Although & 13 & $34 \%$ \\
\hline Total & $\mathbf{3 8}$ & $\mathbf{1 0 0 \%}$ \\
\hline
\end{tabular}

TABLE (1), D

\begin{tabular}{|l|l|l|}
\hline Sequential DMs & Frequency of errors & Percentage of Errors \\
\hline First & 2 & $14 \%$ \\
\hline Second & 5 & $33 \%$ \\
\hline Third & 8 & $53 \%$ \\
\hline Total & $\mathbf{1 5}$ & $\mathbf{1 0 0 \%}$ \\
\hline
\end{tabular}

TABLE 2

\begin{tabular}{|l|l|l|}
\hline Year of study & Frequency of Errors & Percentage of Errors \\
\hline First & 57 & $30 \%$ \\
\hline Second & 54 & $29 \%$ \\
\hline Third & 50 & $27 \%$ \\
\hline Fourth & 26 & $14 \%$ \\
\hline Total & $\mathbf{1 8 7}$ & $\mathbf{1 0 0 \%}$ \\
\hline
\end{tabular}

\section{Question no 1}

1. Fill in the blank with the appropriate following linking words.

(although, and, because, for example, so)

You may use them more than once

Sometimes I wish I were not the middle child in my family-my brother and sisters have an easier life than mine. ---------- my older brother is very responsible; he is like a third parent who we have to respect ------------- obey, --------- he can do whatever he wants. --------- my sisters are very noisy, they get a lot of attention from my parents -they are twins.

\section{Question no 2}

2. Choose the suitable position for the following linking words.

(Because, in order to, instead, third, first, or, second)

You may use them more than once

For people who would like to act in the theater, there are several important rules to remember. make sure that you face your audience while acting because if you turn away from the audience they can't see your facial expressions. make sure that you speak loudly enough have the audience's interest. memorize your lines by rehearsing them often on the train, in the mirror, while you are walking to class. The last and the most important rule is to remain calm on stage if you forget your lines; don't panic and stop speaking the audience will notice that. make up something to say until you remember your next line.

\section{REFERENCES}

[1] AbiSamra, Nada. (2003). An Analysis of Errors in Arabic Speakers' English Writings. American University of Beirut, p. 6.

[2] Al-Buainain, Haifa. (2006). Students Writing Errors in ESL: A Case Study. The University of Qatar.

[3] Asassfeh, Sahail, \& Alshboul, Sabri, \& Alshaboul, Yousef. (2013). Distribution and Appropriateness of Use of Logical connectors in the Academic Writing of Jordanian English-Major Undergraduates. Journal of Educational and Psychological Sciences. Volume 13, Number 3, 15-19.

[4] Daif-Allah, Ayman, \& Albesher, Khaled. (2013). The Use of Discourse Markers in Paragraph Writings: The Case of Preparatory Year Program Students in Qassim University. Canadian Center of Science and Education. Vol. 6, No. 9, $218,217$.

[5] Dijk, Teun. (ed) (1985). Discourse Studies: A Multidisciplinary Introduction. Volume 1. London, Thousand Oaks, New Delhi, $1-2$.

[6] Fraser, Bruce. (1999). What are Discourse Markers? Elsevier Science B.V, Journal of Pragmatics 31, 931-940.

[7] Haselow, A. (2011). Discourse marker and modal particle: The functions of utterance-final then in spoken English. Journal of Pragmatics 43 (14), 3603-3623.

[8] Holmqvist, Kenneth, \& Holsanova, Jana (1997). Focus Movements and the Internal Images of Spoken Discourse. In Liebert, Wolf, \& Redeker, Gisela, \&Waugh, Linda. (eds.), Discourse and Perspective in Cognitive Linguistics. John Benjamins Publication Company, Amsterdam, Philadelphia, p. 224.

[9] Khan, Harunur, and Akter, Md. (2011). Students' Mistakes and Errors in English Writing: Implications for Pedagogy. Center of Research and Training, East West University, p. 11.

[10] Martines C. L. Ana. (2002). The Use of Discourse Markers in E.F.L Learners' Writing. Revista Alicantina de Estudios Ingleses 15, 123-132.

[11] Modhish, Abdulhafeed. (2012). Use of Discourse Markers in the Composition Writings of Arab EFL Learners. Canadian Center of Science and Education. Vol. 5, No. 5, 58-60.

[12] Sadighi, Firooz, \& Heydari, Pooneh. (2012). Cohesion Analysis of L2 Writing: The Case of Iranian Undergraduate EFL Learners. Mediterranean Journal of Social Sciences, Vol. 3(2), 561-562. 
[13] Saez, Fernando. (2003). Culture in Writing: Discourse Markers in English and Spanish Student Writing. Tadea seu liber de Amicitia, Departamento de Didáctica de la Lengua y la Literatura (eds.), Granada, Imprenta Generalife, ISBN 84-688-0899-7, 345- 364, p. 348.

[14] Savage, Alice, \& Mayer, Patricia. (2005). Affective academic writing 2, the short essay. New York, Oxford University press, p. 13.

Farah Mohammad Al Mughrabi was born in Iraq/Baghdad, 30/1/1988. She was graduated from Al Quds School and had the Certificate of Secondary Education in July, 2005. Then, she entered The Hashemite University in Jordan in 2005 to have the Bachelor degree in English Language and Literature in August 2009, with a rating of 3.50 (excellent), listed as an honored student. After that, she continued her study in English Language/linguistics and had the Master degree from The Hashemite University in June 2015 with a rating of 3.91 (excellent), and listed as an honored student.

She worked as a GTA (Graduate Teaching Assistantship) student in the department of English at the Hashemite University in the fall semester of the academic year 2013/2014. She worked as a TUTOR from 1/2016 to 7/2016 as well. She also has a very good skill in using computer and had got ICDL certificate in 2016. 